\title{
BUSINESS INTELLIGENCE EFFECTIVENESS AND CORPORATE PERFORMANCE MANAGEMENT: AN EMPIRICAL STUDY
}

\begin{abstract}
Business intelligence (BI) technologies have received much attention recently from both academics and practitioners, and the emerging field of Business Analytics (BA) is beginning to generate academic research. However, the impact $B I$ and the relative importance of the related field of $B A$ on corporate performance management (CPM) has not yet been investigated. To address this gap, we modelled a CPM framework based on the Integrative model of IT business value and on information processing theory, and subsequently conducted a global survey of senior managers in 337 companies. Partial least squares was employed to analyse the survey data. Findings suggest that the more effective the BI implementation, the more effective the CPM-related planning and analytic practices. BI effectiveness is strongly related to $B A$, planning and to measurement. $B A$ effectiveness in contrast, is strongly related to planning but less so to measurement. The study suggests that although both BI and BA contribute to corporate management practices, the information needs are different based on the level of uncertainty versus ambiguity characteristic of the management practice.
\end{abstract}

Keywords: Business intelligence, Corporate performance management, Empirical Study. 


\section{INTRODUCTION}

Making key strategic decisions in a dynamic business environment is a challenge faced by many organizations today. Although most organizations today perform well in applying management systems in the areas of budgeting, financial and management reporting, and business intelligence analysis, the use of such systems for corporate-level decision making is not as prominent. A corporate performance management (CPM) system is a tool that can help organizations address this challenge. These systems combine management practices and information technologies (IT) to enable organizational performance [22; 93]. Corporate-level management practices determine organizational success because they set the organization's strategy and enable its execution [93]. For example, case studies of Nortel, Circuit City, and Kodak [52; 77; 83] show that poor information processing and analysis, particularly with respect to corporate planning, played a significant role in the failure of these former Fortune 500 companies. Business Intelligence (BI) technologies are thought to support CPM [56], yet, while research suggests that BI can help improve the effectiveness of operational processes $[2 ; 20 ; 28]$, its impact on management practices has been less studied [113].

Organizations have used data to make informed decisions for over 200 years. For example, companies such as Standard Oil and Carnegie Steel in the late 1800s made extensive use of data to improve performance [103]. Since then, analytic methods such as the use of financial ratios and operations research have been adopted by many firms. In today's organizations, the growth of advanced analytics using large volumes of data has led to the creation of advanced analytics functions (which we will refer to as Business Analytics or BA). These practices involve approaches, such as data mining, that look for patterns not discernible using standard BI tools. 
Despite the recent shift towards the term Business Intelligence and Analytics [e.g., 8], traditional BI systems often deliver aggregated data while the statistical methods employed in BA tend to use raw data. Furthermore, it has been argued that organizational needs related to analytic information differ from those related to more transactional information [46; 101]. Therefore, differences exist between these two analytic approaches which suggests that a BI system that extracts and transforms transactional information might not necessarily support BA practices.

Key corporate-level management practices include planning, measurement and analysis [93; 107]. While the BI system might not necessarily support BA due to the different types of information and technologies used, we would expect that the BI system would strongly support planning and measurement. Not all BI systems deliver the capability needed by decision makers [31]. Therefore, exploring the relationship between BI system effectiveness and the effectiveness of corporate-level management practices would provide an indication of the importance of these systems for CPM.

The emerging practice of $\mathrm{BA}$ could be considered a management practice that relies on the $\mathrm{BI}$ system but also influences the other management practices of planning and measurement. Since BA typically relies on raw data for statistical modelling purposes however, we would expect that $\mathrm{BA}$ and the BI system influences planning and measurement management practices in different ways.

Based on the above reasoning, our research questions are as follows: 
1. What is the relationship between the effectiveness of BI system implementation and the effectiveness of corporate-level management practices?

2. To what degree does the BI system influence the BA practice in organizations?

3. What is the relative importance of the BI system versus BA for corporate-level management practices?

Addressing these questions would advance the BI value literature by examining the impact of BI on corporate-level management practices. In addition, assessing the relative impact of BA within CPM adds to the growing literature on the use of BA in organizations. From a theoretical perspective, we extend empirical work on the Integrated Model of IT Business Value to the corporate management domain and introduce Information Processing Theory as an important element in theorizing about information needs for management practices.

The remainder of this article has been structured as follows. The next section reviews the literature. We then outline the research method and discuss the findings. In subsequent sections, the implications for theory and practice are discussed, followed by the inherent limitations of our work and avenues for future research.

\section{LITERATURE REVIEW}


Although the literature characterizes BI in different ways [3; 68; 111], BI tools are generally considered to be software applications that deliver information to decision makers to help maintain business performance $[20 ; 113]$. Most BI systems include different technological components [2; 72] that allow decision makers to view and work with subsets of data [8].

The research questions discussed earlier position this study in the broader domain of IT value, in this case, exploring the degree to which BI system effectiveness enables corporate-level management practices. The Integrative Model of IT Business Value [50] suggests that IT influences operational processes which in turn influence organizational performance. Based on the Resource Based Theory (RBT), IT systems are viewed as internal resources accompanied by complementary assets such as workplace practices that may moderate or mediate the overall impact of IT. Melville et al. [50] point out that one of the weaknesses of the RBT is that it assumes that all resources are used to their full potential. Their model further suggests that the way in which an IT system is deployed depends on IT managerial skill, and research suggests that the level of IT managerial skill influences the quality of the system $[5 ; 6 ; 38]$. Research also suggests that not all organizations derive value from BI because of mismatches between the capability required and that delivered by the BI system [25;31]. The implication is that organizations possess different levels of IT managerial skill which influences the effectiveness to which a BI system is implemented. More effective implementations would lead to better information access and quality to better support corporate-level management practices.

This question of $\mathrm{BI}$ implementation effectiveness is related to the notion of BI maturity. Maturity however, implies a progression in capability in which an organization evolves their BI system 
from fragmented applications to a full enterprise view [37; 71]. Implementation effectiveness may be viewed as the degree to which system implementation meets organizational expectations: whether the system is doing what it was intended to do [26;93]. As previously emphasized in the BI maturity literature, a well-implemented system would provide easy access to high quality information [68]. This would hold true whether it was deployed for a specific business area or across the organization.

Within specific business areas, several authors have demonstrated the impact of BI systems on sales, marketing, and inventory management $[2 ; 20 ; 18]$. In a review of the BI impact literature, Aruldoss et al. [2] suggest that for sales and marketing, the BI system provides information on customer needs across many customer segments to help managers better match products to market demand. For inventory management, a BI system could provide historical information on stock-outs or inventory carrying costs thus permitting better forecasting. These types of situations fall under the category of "management control" that requires an exchange of information from operational levels to responsible managers and vice versa [41]. For some of these decisions, business rules could be programmed into the BIS [20;33] to speed up information processing.

No such evidence is available for the impact of BI on corporate-level management practices. One might conjecture, however, that the BI system provides historical information and permits an exchange of information among managers similar to its role in operational processes. The information needs of management practices however, differ from that of operational processes. 
Recently, information processing theory has been invoked to explore the question of information needs related to BA [7; 36]. This theory argues that organizations strive to fit information capability to information requirements. Task uncertainty generates higher information needs and when uncertainty persists despite the delivery of additional information, buffers are often used. For example, in the case of inventory management, firms might hold "safety stocks" when managers are unsure about the level of demand for their products [69]. Equivocality, defined as “...the multiplicity of meaning conveyed by information about organizational activities" [11, p. $211]$ is another important element of information processing theory. In this situation, information is available, but considerable ambiguity exists such that decision makers are not confident about what course of action to follow.

Ambiguity is often present in non-routine, complex tasks and can be resolved through the selection of "rich" media. Media richness is defined as the information carrying capacity of an information medium [13]. The richest medium is face-to-face communication. In ambiguous situations, face-to-face encounters can help to better frame the problem and explore multiple courses of action. Empirical support for this theory is provided by Kowalczyk \& Buxmann [36] who demonstrate that companies facing complex decisions use group meetings more often during the decision-making process. In contrast, decisions that were considered routine relied exclusively on the BA process.

Media richness theory was developed in the late 1980s. Considering modern analytic capabilities in organizations, ambiguity reduction can be viewed from a different perspective. The BI system, for example, might serve to reduce uncertainty by delivering large amounts of information. For 
operational decisions, where the outcome is often clear and various models exist to help determine specific courses of action, information volume might well serve the needs of decision makers. The BI system might also help to reduce information overload through data aggregation. On the other hand, methods used in BA, such as data-mining, could reduce ambiguity by sorting through large volumes of data to discover meaningful patterns. Therefore, while a BI system might be directly useful for decisions characterized by low complexity, BA might be of more importance for situations featuring more complex and thus ambiguous decision-making conditions as often found in corporate planning and management practices.

These corporate-level management practices may be viewed as a set of habitual activities designed to establish and implement the organization's strategy [93]. A practice is defined as a "habitual or customary operation"1: a series of activities done the same way each time the practice is implemented. A method is a particular form of procedure. Research demonstrates that organizations use a wide range of different tools and techniques [79;99] integrated into higherlevel management practices. The practice of management accounting for example, includes methods such as Activity-Based Costing or Balanced Scorecards, each implemented following a set of specific procedures [9]. Similarly, a corporate-level management practice such as planning would involve methods that include environmental scanning, SWOT (strengths, weaknesses, opportunities and threats) analysis, or strategy mapping. For the purposes of this study, we define these practices as corporate-level customary operations that include a variety of different methods.

\footnotetext{
${ }^{1}$ Similar definitions can be found in any of the major English language dictionaries.
} 
In the context of information processing theory, planning is arguably a complex process where managers integrate external and internal information to chart a course for the company. It has been argued in fact, that planning is itself an information gathering exercise [82]. The practice of measurement by contrast, involves defining performance indicators, gathering and analyzing current performance versus expectations and then taking corrective action as required [41]. Measurement therefore could feature less equivocality because organizational objectives would provide a context for the measures being used. For example, targets are often set for sales or for customer satisfaction. The measure compared to the target provides unambiguous feedback about current performance.

In summary, based on the integrative model of IT value, we argue that BI system implementation effectiveness influences process effectiveness through its influence on three CPM practices: planning, measurement and analytics. The practice of BA in turn, also influences planning and measurement. Figure 1 outlines the research model based on the above argument. Consistent with the Integrative Model of IT Business Value, the two management practices of planning and measurement are thought to directly influence process effectiveness (used here as the proxy for organizational performance). These two practices contribute to process effectiveness because they represent different forms of control mechanisms [96]. Planning can be considered a "feedforward" mechanism in that it helps to ensure that employees design processes that accomplish business objectives. Measurement is a feedback mechanism to permit ongoing course correction. Both control mechanisms work in tandem [112] to enable organizational success through effective process management. 


\section{RESEARCH METHOD}

\section{Data Collection}

This study was conducted in collaboration with two industry partners, PricewaterhouseCoopers (PwC) and the Canadian Advanced Technology Association (CATA). These industry partners collectively represent more than 50 years of experience in the field of performance management and therefore they confirmed face and content validity of the survey used in collecting data. Specifically, the partners had worked with many of the organizations involved in the study and therefore helped to identify the specific techniques involved in the CPM practices. The study used an online survey method for data collection. Survey questions were developed based on the research hypotheses and on feedback from the industry partners. The questions went through three rounds of reviews by a sub-set of respondents in the partner organizations. Survey respondents were recruited through e-mail invitations distributed to 1,300 senior managers from PwC's and CATA's databases. A total of 337 complete responses were received and analysed using the Partial Least Squares (PLS) with the SmartPIS 3 software [80]. PLS-SEM was selected because of the exploratory nature of the study.

Given our focus on CPM, we targeted senior managers, executives and board members of the companies surveyed. The intent was to elicit the assessment of the most senior level managers who would have a corporate viewpoint of BI system implementation and CPM practice effectiveness. It has been argued that these executives can accurately perceive the value of IT 
investments through distributed sensemaking [102] because they often approve the BI system expenditures and they are closely involved in many of the CPM practices. Moreover, their assessments tend to be accurate when compared with objective measures of the same phenomena [20] and the best way to assess user perceptions of system effectiveness is to ask them [31].

Since the informants provided responses to the dependent and independent variables, the marker variable statistical test was adopted to estimate the impact of Common Method Variance (CMV). Following Lindell and Whitney [40], a scale measuring the quality of information provided to the board of directors (Cronbach's alpha of 0.85 ) was included and used as a "marker" variable since it was thought to be theoretically unrelated to the dependent variable. This variable was comprised of four measures: information related to customers, employees, innovation and the impact of company activities on the environment. The PLS algorithm demonstrated high validity of the construct (t-values of the measurement variables ranged from 38 to 128 and factor loadings from 0.96 to 0.98 ). The correlation of the marker variable to other constructs in the study ranged from 0.02 to 0.08 with $\mathrm{t}$-values ranging from 0.15 to 0.70 . The largest correlation accounted for only 0.006 of one of the constructs (measurement effectiveness), which led us to conclude the CMV is not a problem in this study.

\section{Constructs and Measures}

The logic of a PLS-based study is that unobservable constructs can be measured by gathering information on observable items related to that the construct. In this study, the central construct is the effectiveness of the BI system and CPM practices as measured by the perceived effectiveness 
of related components and methods (the observable measures in this case). We relied on guidance from the industry partners and on the published literature to define the constructs and the measures.

A considerable debate has emerged about the use of reflective and formative constructs in PLSbased research [1.a.i.1; $10 ; 17 ; 32 ; 39 ; 64 ; 81 ; 108]$. One area of consensus emerging from this debate is that constructs could be modelled either as formative or reflective based on theory and on the objectives of the research. Jarvis et al., [32] defined four basic criteria for determining whether constructs should be modelled as formative or reflective. The first criterion refers to the direction of causality, does the does the construct determine the measures or do the measures determine the construct? Coltman et al., [10] suggest that whether the construct exists independently of the measures is also important and Petter et al., [64], argue that one should also consider whether all measures reflect a common theme. If so, the construct would be perceived as unidimensional and therefore reflective. The second criterion is the degree to which measures are interchangeable such that the construct does not change as the measures change. The third is the the degree to which the measures are correlated, and the fourth considers whether the measures have similar antecedents and consequences.

In this study, respondents assessed the effectiveness of specific components of the BI system and the methods used in the three management practices to form an aggregate evaluation of overall effectiveness. We will apply the four criteria to assess the BI system effectiveness construct as representative of all constructs in the study. Conceptually speaking, BI system effectiveness (defined as the degree to which the system delivers what it is supposed to deliver) could exist without the existence of the BI system itself. For example, during the planning stages, managers 
would consider the BI capability needed [31]. This capability requirement defines in fact, the "effectiveness" needed from the BI system, and specific BI system components would be selected and implemented based on the planned requirements. The effectiveness of each of these specific components provides an overall measure of effectiveness of the BI system.

In terms of the second criterion, these specific components are interchangeable because our interest was on the aggregate notion of BI system effectiveness, not on any of the specific components themselves. Accordingly, the measures carry a common theme (i.e., does each component do what it was meant to do) that provides for an assessment of the overall system.

For the third criterion, it is difficult to know a priori if the measures are related, but one assumes that if an organization effectively implements one BI system component, the others will also be implemented effectively. Finally, with respect to the fourth criterion, each component would have similar antecedents and consequences: the BIS is implemented to solve information delivery issues and results in improved access to information. The consequence of a well implemented system is that decision makers have access to high-quality information [68]. This reasoning holds for all components of a BI system thus the measures have similar antecedents and consequences.

The survey questions focused on BI system implementation and management practice effectiveness. In this case, effectiveness referred to the degree to which the BI system and the management practices achieved the intended goals [26;93]. Respondents were asked to record 
their perceptions of effectiveness on a scale of 1 to 7 with 7 meaning "highly effective". The overall score for effectiveness for each construct was the mean of the associated components and methods.

\section{Validity and Reliability}

Convergent validity is confirmed when measurement items load more highly on their latent constructs than on any other construct and show a significant t-value [23]. Tables 1 and 2 provide the factor loadings for all constructs showing that their measures do in fact load significantly ( $p$ $<=0.01)$.

Insert Table 1 here

Insert Table 2 here

Discriminant validity is demonstrated when the average variance extracted (AVE) related to the latent construct is at least 0.50 and when the square root of the AVE is larger than the correlation of the construct with any other construct. Table 3 confirms that this is indeed the case.

Insert Table 3 here 


\section{Control Variables}

Research suggests that organizational size [30] and industry sector [16;20] can influence the ways in which CPM is employed in organizations. Accordingly, size and industry sector are considered as control variables for this study. For organization size, we use the number of employees as the basis for creating categories of small (less than 250 employees, 139 cases) and large (250 or more employees, 198 cases) organizations. For the sector variable, we collapsed the various industry sectors represented into service (200 cases) and non-service (137 cases) based on the argument that firms differ most markedly in their use of CPM systems along this line of delineation [20].

In addition, it is possible that companies in Asia use BI systems differently than do North American companies [115]. Accordingly, we also collapsed the sample into East (China and Japan, 88 cases) and West (North America, 225 cases). Companies that did not fit into these categories were eliminated from the data set. 


\section{RESEARCH RESULTS}

Table 4 displays demographic information on the respondents and their organizations.

Insert Table 4 here

Figure 2 provides the results of the PLS analysis (t-values in brackets). In Figure 2, we note a strong relationship between BI system implementation effectiveness and the effectiveness of BA. This finding indicates that the BI system might help to organize data for use in BA. The $\mathrm{R}^{2}$ is 0.336, however, indicating that BI system effectiveness accounts for a moderate portion of the variance in BA effectiveness. We consider two factors to explain this result. First, BI system use is voluntary: decision makers could access information from different sources [4]. Second, in many BI systems data are aggregated, but advanced analytics typically requires the use of raw data. Accordingly, as more advanced analytics techniques are adopted in organizations, the use of BI system-based aggregated data might decline in favour of storage systems (such as data lakes) that maintain data in more granular formats.

Insert Figure 2 here

Table 5 displays effect sizes for the relationships in the research model. BI system effectiveness has a strong influence on all management practices. The impact of BA is not as pronounced and 
its effect size is not significant for measurement but it is for planning. This finding is consistent with information processing theory because, as previously discussed, planning could be considered a more ambiguous management practice than measurement. Accordingly, the application of more sophisticated analytic models might be used more so than in measurement.

We can see that measurement has a strong relationship (0.461) with process effectiveness while planning has a weaker (0.375) but still significant relationship. These findings could be explained through control theory [41]. Planning is a feedforward mechanism and at corporate levels in the organization, is often done once a year. Measurement by contrast is a feedback device that is used on an ongoing basis to help make mid-course corrections to organizational activities.

Insert Table 5 here

Insert Table 6 here

Considering Tables 5 and 6 , we conclude that BI system effectiveness strongly influences BA and has a weaker but significant relationship with the other management practices. By contrast, BA has a significant impact on planning, but its effect on measurement is small and not as 
important. Table 5 shows that both the BI system and BA significantly impact process effectiveness, but the weight for the BI system is significantly higher than for BA.

\section{Control Variables}

We examined potential heterogeneity of the findings using the control variables identified earlier in this paper by comparing the outer loadings of the measurement model subsets. A comparison of the regression weights was performed using the PLS-MGA approach [27]. The only significant finding was a difference in the $\mathrm{R}^{2}$ for the measurement practice between large $\left(\mathrm{R}^{2}=0.224\right)$ and small organizations $\left(\mathrm{R}^{2}=0.297\right)$. This appeared to be the result of a combined effect of a stronger link between the BI system and BA for smaller firms ( 0.617 versus 0.572$)$ and between analytics and measurement $(0.212$ versus 0.137$)$. Overall, it suggests that smaller firms rely more on analytics to inform their measurement practice.

\section{DISCUSSION}

This exploratory research project examined the relationship between the effectiveness of BI system implementation and the effectiveness of CPM practices. We also explored the relative importance of the BI system versus BA.

This study shows a positive and significant relationship between BI system implementation effectiveness and the key corporate management practices of BA, planning and measurement. The strength of the relationship differs among the practices however. The BI system effectiveness shows a strong relationship to BA effectiveness (0.581) accounting for $33.6 \%$ of its variance. Given that in this study, the BI system was positioned as an information delivery tool, 
this finding suggests that BA processes in organizations rely on the BI system, but that other sources of information are also used. Clearly, other factors would contribute to BA effectiveness such as the skills of the analysts and the processes being used. The finding does suggest however, that the BI system plays a positive role in BA effectiveness.

The total effects calculations show that BI system effectiveness is strongly related to measurement (0.499), planning (0.566) and process effectiveness $(0.444)$. BA effectiveness by contrast, shows a weak relationship to measurement $(0.204$, effect size of 0.042$)$ and to process effectiveness ( 0.211$)$ but a stronger relationship to planning ( 0.311 , effect size of 0.108$)$. Given that planning is thought to be a management practice characterized by higher levels of ambiguity than measurement, this finding is consistent with information processing theory in that BA practices such as data mining can be used to help reduce the ambiguity present in large amounts of data.

Planning and measurement influence process effectiveness to different degrees $(0.377$ and 0.459 respectively). Measurement has a stronger relationship which might result from the fact that planning occurs less frequently in organizations than does measurement. Yet both function as control mechanisms that help the organization identify the right types of processes to put in place and provide feedback to continually modify processes as needed.

The study reveals that BI system effectiveness is related to the effectiveness of important CPM practices but with different levels of influence. Overall, the BI system shows a stronger influence than the BA function. This might be because BA is relatively new in organizations, or it might be 
due to the different frequencies with which organizations conduct the different corporate-level management practices. Alternatively, many BI systems now include basic analytic functionalities (i.e., for forecasting and trend analysis), therefore it is possible that many previously specialized BA functions are being built into new BI system tools.

\section{Implications}

The study has several important implications for theory. First, it confirms the Integrative Model of IT Business Value for corporate-level management practices. It also introduces the notion of control practices at the corporate level of analysis. These might in fact, be representative of the "workplace" practices noted in this model that influence the degree to which the system itself positively impacts organizational performance. The study also provides some validation of information processing theory in the context of the different uses of information in BI and BA. This is an important issue particularly considering the differences noted between transactional and analytic information delivery [101] and types of IT managerial skill needed to implement systems that support the different information needs. As the use of BA increases in organizations, it would be important to understand the different skill sets, both of IT staff who implement these systems, and of the managers and decision makers who need to interpret the analyses.

The study also suggests that advanced analytics capabilities in modern organizations might call for a revisiting of the concept of media richness. This theory was developed in the late 1980s where the emphasis was on the information carrying capacity of the channel between the sender and the receiver [13]. In modern organizations where BA practices have become more 
sophisticated, perhaps the notion of media richness can now be expanded to include the interpretation systems of the receiver. That is, sophisticated analytic methods such as data mining or artificial intelligence algorithms might serve the purpose of reducing ambiguity in place of or in concert with media-rich channels of communication.

This research offers several implications for practice, especially for BI stakeholders who are involved in planning, reviewing or implementing BI to support CPM. BI adoption has become widespread as organizations continue to search for ways to support business performance management. Yet, it has been reported that between $70 \%$ and $80 \%$ of BI projects fail due to inadequate communication between IT and business users about the specific uses of the tools being implemented [25].

For organizations that wish to explore BI tools to support CPM, this study suggests that a consideration of purpose of the tools-uncertainty versus ambiguity reduction-can help determine the blend between standard BI and more advanced BA packages. An important aspect to consider however is IT managerial skill in implementing and supporting the use of the tools postimplementation.

\section{Limitations and future research}

The findings of the study should be interpreted in the light of a few limitations. Because we focused our attention on CPM, we gathered information from senior managers in the participating organizations. Additional research focusing on the middle management layers might shed more insight on the research questions. Moreover, the use of additional variables such as the competence of staff to use BI tools might help to better explore the linkages of BI to process effectiveness. 
Nevertheless, the study provides an important first step in examining how BI influences CPM practices in organizations and establishes a foundation for future research that might include data collection from managers at different layers in the organizational hierarchy and the use of longitudinal approaches to better understand the specific mechanisms through which BI supports CPM over time.

\section{REFERENCES}

1. Amaro, S., \& Duarte, P. "Modelling Formative Second Order Constructs in PLS," Proceeding of the 15th European Conference on Research Methodology for Business and Management Studies, Kingston, UK, 2016.

2. Aruldoss, M., Travis, M. L., \& Venkatesan, V. P. "A survey on recent research in business intelligence," Journal of Enterprise Information Management 27: (6), 2014, 831-866.

3. Baars, H., \& Kemper, H. G. "Management support with structured and unstructured data: an integrated business intelligence framework," Information Systems Management 25: (2), 2008, 132-148.

4. Bischoff, S., Aier, S., Winter, R., \& Haki, M. K. "Understanding continuous use of business intelligence systems: A mixed methods investigation," Journal of Information Technology Theory and Application 16: (2), 2015, 5-38.

5. Boynton, A., Zmud, R., \& Jacobs, G. "The influence of IT management practice on IT use in large organizations," MIS Quarterly 18: (3), 1994, 299-318.

6. Byrd, T. A., \& Turner, D. E. "An exploratory analysis of the value of the skills of IT personnel," Decision Sciences 32: (1), 2001, 21-54. 
7. Cao, G., Duan, Y., \& Li, G. "Linking business analytics to decision making effectiveness: A path model analysis," IEEE Transactions on Engineering Management 62: (3), 2015, 384-395.

8. Chen, H., Chiang, R. H., \& Storey, V. C. "Business intelligence and Analytics: From big data to big impact," MIS Quarterly 36: (4), 2012, 1165-1188.

9. Chenhall, R. H., \& Langfield-Smith, K. "Adoption and benefits of management accounting practices: An Australian study," Management Accounting Research 9, 1998, $1-19$.

10. Coltman, T., Devinney, T. M., Midgley, D. F., \& Venaik, S. "Formative versus reflective measurement models: Two applications of formative measurement," Journal of Business Research 61: (12), 2008, 1250-1262.

11. Daft, R. L., \& Macintosh, N. B. "A tentative exploration into the amount and equivocality of information processing in organizational work units," Administrative Science Quarterly 26: (2), 1981, 207-224.

12. Daft, R., \& Weick, K. "Toward a model of organizations as interpretation systems," Academy of Management Review 9, 1984, 284-295.

13. Daft, R., Lengel, R., \& Trevino, L. "Message equivocality, media selection and manager performance: Implications for Information Systems," MIS Quarterly 11: (3), 1987, 335366.

14. Davenport, T. "Competing on Analytics," Harvard Business Review, 2006, 2-10.

15. Davenport, T. H. "Business Intelligence and Organizational Decisions," International Journal of Business Intelligence Research 1: (1), 2010, 1-12.

16. Dehning, B., \& Richardson, V. J. "Returns on investment in information technology: A research synthesis," Journal of Information Systems 16: (1), 2002, 7-30.

17. Diamantopoulos, A., Riefler, P., \& Roth, K. P. "Advancing formative measurement models," Journal of Business Research 61: (12), 2008, 1203-1218.

18. Dobbs, T., Stone, M., \& Abbott, J. "UK data warehousing and business intelligence implementation," Qualitative Market Research 5: (4), 2002, 235-238.

19. Dutot, V., Bergeron, F., \& Raymond, L. "Information management for the internationalization of SMEs: An exploratory study based on a strategic alignment perspective," International Journal of Information Management 34, 2014, 672-681.

20. Elbashir, M. Z., Collier, P. A., \& Davern, M. P. "Measuring the effects of business intelligence systems: The relationship between business process and organizational performance," International Journal of Accounting Information Systems 9, 2008, 135 153.

21. Fetzner, M., \& Freitas, H. "Business Intelligence (BI) Implementation from the perspective of individual change," Journal of Information Systems and Technology Management 8: (1), 2011, 25-50.

22. Frolick, M., \& Ariyachandra, T. "Business performance management: one truth," Information Systems Management 23: (1), 2006, 41-48.

23. Gefen, D., \& Straub, D. "A practical guide to factorial validity using PLS-Graph: Tutorial and annotated example," Communications of the Association for Information Systems 16, 2005, 91-109.

24. Gilad, T., \& Gilad, B. "SMR Forum: Business intelligence-the quiet revolution," Sloan Management Review 27: (4), 1986, 53-61. 
25. Goodwin, B. "Poor communication to blame for business intelligence failure, says Gartner," 2011, Retrieved 2013 йил 5-May from ComputerWeekly.com: www.computerweekly.com/news/1280094776/Poor-communication-to-blame-forbusiness-intelligence-failure-says-Gartner

26. Grubljesic, T., \& Jaklic, J. "Conceptualization of the business intelligence extended use model," The Journal of Computer Information Systems 55: (3), 2015, 72-82.

27. Hair, J. T., Hult, G. T., Ringle, C. M., \& Sarstedt, M. A Primer on Partial Least Squares Structural Equation Modeling (PLS-SEM), Thousand Oaks, CA: Sage Publications, 2014.

28. Hocevar, B., \& Jaklic, J. "Assessing benefits of business intelligence systems: a case study," Management 15: (1), 2010, 87-119.

29. Holsapple, C., Lee-Post, A., \& Pakath, R. "A unified foundation for business analytics," Decision Support Systems 64, 2014, 130-141.

30. Hoque, Z., \& James, W. "Linking BSC measures to size and market factors: Impact on organizational performance," Journal of Management Accounting Research 12, 2000, 1 17.

31. Isik, O., Jones, M. C., \& Sidorova, A. "Business intelligence success and the role of BI capabilities," Intelligent Systems in Accounting, Finance and Management 18, 2011, 161176.

32. Jarvis, C. B., MacKenzie, S. B., \& Podsakoff, P. M. “A critical review of construct indicators and measurement model misspecification in marketing and consumer research," Journal of Consumer Research 30: (2), 2003, 199-218.

33. Kaula, R. "Business intelligence rationalization: A business rules approach," International Journal of Information, Business and Management 7: (1), 2015, 129-143.

34. Korhonen, P., Mano, H., Stenfors, S, \& Wallenius, J. "Inherent Biases in Decision Support Systems: The Influence of Optimistic and Pessimistic DSS on Choice, Affect, and Attitudes," Journal of Behavioral Decision Making 21, 2008, 45-58.

35. Koutsoukis, N. S., \& Mitra, G. Decision Modelling and Information Systems, Boston: Kluwer Academic Publishers, 2003.

36. Kowalczyk, M., \& Buxmann, P. "Big data and information processing in organizational decision processes," Business and Information Systems Engineering 5, 2014, 267-278.

37. Lahrmann, G., Marx, F., Winter, R., \& Wortmann, F. "Business intelligence maturity: Development and evaluation of a theoretical model," Proceedings of the 44th Hawaii International Conference on Systems Sciences, Hawaai, 2011.

38. Larosiliere, G. D., McHaney, R., \& Kobelsky, K. "The effects of IT management on technology integration," Journal of Computer Information Systems 56: (4), 2016, 341351.

39. Lee, N., \& Cardogan, J. W. "Problems with formative and higher-order reflective variables," Journal of Business Research 66, 2013, 242-247.

40. Lindell, M. K., \& David J. W. "Accounting for common method variance in crosssectional research designs," Journal of applied psychology 86: 1, 2001, 114.

41. Long, C. P., Sitkin, S. B., Cardinal, L. B., \& Burton, R. M. "How controls influence organization information processing: insights from a computational modeling investigation," Comput Math Organ Theory 21, 2015, 406-436.

42. Luhn, H. P. "A business intelligence system," IBM Journal of Research and Development 2: (4), 1958, 314-319. Retrieved 2012 йил 5-August from A business intelligence system: http://www.research.bim.com/journal/rd/024/ibmrd0204.pdf 
43. Lukman, T., Hackney, R., Popovic, A., Jaklic, J., \& Irani, S. "Business intelligence maturity: The economic transitional context within Slovenia," Information Systems Management 28, 2011, 211-222.

44. Maholtra, N. K., Kim, S. S., \& Patil, A. "Common method variance in IS research: a comparison of alternative approaches and a reanalysis of past research," Management Science 52: (12), 2006, 1865-1883.

45. Manyika, J., Chui, M., Brown, B., Bughin, J., Dobbs, R., Roxburgh, C., \& Hung Byers, A. Big data: The next frontier for innovation, competition and productivity. Mckinsey \& Company, 2011.

46. March, S. T., \& Hevner, A. R. "Integrated Decision Support Systems: A data warehousing perspective," Decision Support Systems, 2007, 1031-1043.

47. Matusik, S. F., \& Heeley, M. B. "Absorptive capacity in the software industry: identifying dimensions that affect knowledge and knowledge creation activities," Journal of Management 31, 2005, 549-572.

48. May, T. The New Know: Innovation Powered by Analytics, Boston: John Wiley and Sons, 2009.

49. Mayers, R. E., \& Moreno, R. "Nine Ways to Reduce Cognitive Load in Multimedia Learning," Educational Psychologist 38: (1), 2003, 43-52.

50. Melville, N., Kraemer, K., \& Gurbaxani, V. "Information Technology and performance: An integrative model of IT business value," MIS Quarterly 28: (2), 2004, 283-322.

51. Micheli, P., \& Manzoni, J. F. "Strategic performance measurement: benefits, limitations and paradoxes," Long Range Planning 43, 2010, 465-476.

52. Moore, S. Profile of Kodak: from Film to Digital Photography, University of Michigan, William Davidson Institute, 2010.

53. Moyer, D. Defining and measuring competencies, Click to Learn, 2001.

54. Mukhopadhyay, T., Kekre, S., \& Kalathur, S. "Business value of Information Technology: A study of electronic data interchange," MIS Quarterly 19: (2), 1995, 137156.

55. Muller, R. M., Linders, S., \& Pires, P. L. "Business Intelligence and service-oriented architecture: A Delphi study," Information Systems Management 27, 2010, 168-187.

56. Negash, S. "Business Intelligence," Communications of the Association for Information Systems 13, 2004, 177-195.

57. Niu, 1., Lu, J., \& Zhang, G. Cognition-Driven Decision Support for Business Intelligence. Berlin: Springer-Verlag, 2009.

58. Nonaka, I., \& Takeuchi, H. The Knowledge Creating Company: How Japanese Companies Create the Dynamics of Innovation, New York: Oxford University Press, 1995.

59. Nonaka, I., Konno, N., \& Toyama, R. Emergence of BA: A conceptual framework for the continuous and self-transcending process of knowledge creation, In I. N. (Eds), Knowledge Emergence. New York: Oxford University Press, 2001.

60. O'Dell, C., \& Grayson, C. J. If Only we Knew what we Know: The Transfer of Internal Knowledge and Best Practices, New York, NY: The Free Press, 1998.

61. Otim, S., Dow, K. E., Grover, V., \& Wong, J. "The impact of information technology investments on downside risk: Alternative measurement of the business value of IT," Journal of Management Information Systems 29: (1), 2012, 159-194. 
62. Otley, D. "Performance management: a framework for management control systems research," Management Accounting Research 10, 1999, 363-382.

63. Perry, J., \& Rainey, H. "The public-private distinction in organization theory: A critique and research strategy," Academy of Management Review 13: (2), 1988, 192-201.

64. Petter, S., Straub, D., \& Rai, A. "Specifying formative constructs in Information Systems research," MIS Quarterly 31: (4), 2007, 623-656.

65. Piaget, J. The Psychology of Intelligence, New York: Routledge, 1950.

66. Pilichowski, E. Results of the survey of knowledge management practices for ministries/departments/agencies of central government in OECD member countries, 2003. (O. Public Governance and Territorial Development Directorate, Producer)

Retrieved 2011 йил 12-December from http://www.oecd.org/dataoecd/24/63/2496135.ppt

67. Podsakoff, P. M., MacKenzie, S. B., Lee, J. Y., \& Podsakoff, N. P. "Common method biases in behavioural research: A critical review and recommended strategies," Journal of Applied Psychology 88: (5), 2003, 879-903.

68. Popovic, A., Hackney, R., Simoes Coelho, P., \& Jaklic, J. "Towards business intelligence systems success: Effects of maturity and culture on analytical decision making," Decision Support Systems 54, 2011, 729-739.

69. Premkumar, G., Ramamurthy, K., \& Stoak-Saunders, C. "Information processing view of organizations: An exploratory examination of fit in the context of interorganizational relationships," Journal of Management Information Systems 22: (1), 2005, 257-294.

70. Rainey, H. "Public management: recent research on the pological context and managerial roles, structures and behaviors," Journal of Management 15: (2), 1989, 229-250.

71. Rajteric, H. “Overview of business intelligence maturity models," Management 15: (1), 2010, 47-67.

72. Ramakrishnan, T., Jones, M. C., \& Sidorova, A. "Factors influencing business intelligence data collection strategies: an empirical investigation," Decision Support Systems 52, 2012, 486-496.

73. Randall, R., Ferguson, E., \& Patterson, F. "Self-assessment accuracy and assessment centre decisions," Journal of Occupational and Organizational Psychology 73, 2000, 443-459.

74. Ranjan, J. "Business justification with business intelligence," VINE: Journal of Information and Knowledge Management Systems 38: (4), 2008, 461-475.

75. Rashman, L., Withers, E., \& Hartley, J. "Organizational learning and knowledge in public sector organizations: a systematic review of the literature," International Journal of Management Reviews 11: (1), 2009, 463-494.

76. Richards, G. S., \& Duxbury, L. "Work-group knowledge acquisition in knowledge intensive public sector organizations: An exploratory study," Journal of Public Administration Research and Theory, 2014. doi:10.1093/jopart/muuo34

77. Richards, G., Mirabeau, L., Calof, J., \& Mignerat, M. “A process view of organizational failure: The case of Nortel," Academy of Management Conference, Philadelphia, 2014.

78. Riege, A., \& Lindsay, N. "Knowledge management in the public sector: stakeholder partnerships in the public policy development," Journal of Knowledge Management 10: (3), 2006, 24-39.

79. Rigby, D., \& Bilodeau, R. Management tools and trends, 2009, Bain and Company, 2009. 
80. Ringle, C M; Wende, S; Becker, J M. SmartPls 3, Boenningstedt, SmartPLS GmbH, http://smartpls.com.

81. Roberts, N., \& Thatcher, J. B. "Conceptualizing and testing formative constructs: Tutorial and annnotated example," The DATA BASE for advances in Information Systems 40: (3), 2009, 9-39.

82. Rogers, P. R., Miller, A., \& Judge, W. Q. "Using information-processing theory to understand planning/performance relationships in the context of strategy," Strategic Management Journal 20, 1999, 567-577.

83. Romero, J. "The Rise and Fall of Circuit City," Economic History, 2013, 1-3.

84. Rubenstein-Monanto, B., Buchwalter, J., \& Liebowitz, J. "Knowledge management: A US social administration case study," Government Information Quarterly 18, 2001, 223253.

85. Sahay, B. S., \& Ranjan, J. "Real time business intelligence in supply chain analytics," Information Management and Computer Security 16: (1), 2008, 28-48.

86. Sambamurthy, V., Bharadwaj, A., \& Grover, V. "Shaping agility through digital options: Reconceptualizing the role of IT in contemporary firms," MIS Quarterly 27: (2), 2008, 237-263.

87. Sarin, S., \& McDermott, M. "The effect of team leader characteristics on learning, knowledge application and performance of cross-functional new product development teams," Decision Sciences 34, 2003, 707-739.

88. Scherbaum, C. A., \& Ferreter, J. M. "Estimating statistical power and required sample sizes for organizational research using multilevel modelling," Organizational Research Methods 12: (2), 2009, 347-367.

89. Schultze, U., \& Stabell, C. "Knowing what you don't know: discourses and contradictions in knowledge management research," Journal of Management Studies 41: (4), 2004, 549573.

90. Schulz, M. "The uncertain relevance of new knowledge: organizational learning and knowledge flows," Academy of Management Journal 44, 2001, 661-677.

91. Seddon, P. B., Constantinidis, D., \& Dod, H. "How does Business Analytics contribute to Business Value?," Thirty third International Conference on Information Systems, Orlando, 2012.

92. Sessa, V., \& London, M. "Interventions to stimulate group learning in organizations," Journal of Management Development 27, 2008, 554-573.

93. Sharma, R. S., \& Djiaw, V. "Realising the strategic impact of business intelligence tools," VINE 41: (2), 2011, 113-131.

94. Shrauger, S. J., \& Osberg, T. M. "The relative accuracy of self-prediction and judgements by others in psychological assessment," The Psychological Bulletin 90, 1981, 322-351.

95. Simon, H. A. “A behavioral model of rational choice," The Quarterly Journal of Economics 69: (1), 1955, 99-118.

96. Simons, R. Levers of Control, Boston: Harvard Business School Press, 1995.

97. Snijders, T., \& Bosker, R. Multilevel Analysis, London: Sage Publications, 1999.

98. Speckbacher, G., Bischoff, J., \& Pfeiffer, T. "A descriptive analysis on the implementation of Balanced Scorecards in German-speaking countries," Management Accounting Research 14, 2003, 361-387. 
99. Stenfors, S., Tanner, L., Syrjanan, M., Seppala, T., \& Haapalinna, I. "Executive views concerning decision support tools," European Journal of Operational Research 181, 2007, 929-938.

100. Stock, G., Greis, N., \& Fischer, W. “Absorptive Capacity and new product development," Journal of High Technology Management Research 12, 2001, 77-91.

101. Stroh, F., Winter, R., \& Wortmann, F. "Method support of information requirements analysis for analytical information systems," Business and Information Systems Engineering 3: (1), 2011, 33-43.

102. Tallon, P. P. "Do you see what I see? The search for consensus among executives' perception of IT business value," European Journal of Information Systems 23, 2014, 306-325.

103. Tedlow, R. S. Giants of Enterprise: Seven Business Innovations and the Empires they Built, New York: Harper Row, 2003.

104. Titus Jr., V. K., Covin, J. G., \& Slevin, D. P. “Aligning strategic processes in pursuit of firm growth," Journal of Business Research 64: (5), 2011, 446-453.

105. Todorova, G., \& Durisin, B. "Absorptive capacity: valuing a reconceptualization," Academy of Management Review 22, 2007, 774-786.

106. Tsai, W. "Knowledge transfer in intraorganizational networks: effects of network position and absorptive capacity on business unit innovation and performance," Academy of Management Journal 44, 2001, 996-1004.

107. Turban, E., Sharda, R., \& Delen, D. Decision Support and Business Intelligence Systems, New York: Pearson, 2011.

108. Urbach, N., \& Ahlemann, F. "Structural Equation Modeling in Information Systems research using Partial Least Squares," Journal of Information Technology Theory and Application 11: (2), 2010, 5-40.

109. Vinekar, v., Teng, J. T., \& Chennamaneni, A. "The interaction of business intelligence and knowledge management in organizational decision-making," Journal of International Technology and Information Management 18: (2), 2009, 143-259.

110. Vuksic, V. B., Bach, M. P., \& Popovic, A. "Supporting performance management with business process management and business intelligence: A case analysis of integration and orchestration," International Journal of Information Management 33, 2013, 613-619.

111. Watson, H. J., \& Wixom, B. H. "The current state of business intelligence," Computer 40: (9), 2007, 96-99.

112. Widener, S. K. "An empirical analysis of the levers of control framework," Accounting, Organizations and Society 32, 2007, 757-788.

113. Wieder, B., \& Ossimitz, M.-L. "The impact of Business Intelligence on the quality of decision making-a mediated model," Procedia Computer Science 64, 2015, 1163-1171.

114. Wixom, B. H., Watson, H. J., Reynolds, A., \& Hoffer, J. A. "Continental Airlines continues to soar with Business Intelligence," Information Systems Management 25, 2008, 102-112.

115. Yeoh, W., Richards, G., \& Wang, S. "Benefits and barriers to Corporate Performance Management systems," Journal of Computer Information Systems, 2014. 105-116. 
